\title{
Chlorination of Taurine by Human Neutrophils
}

\author{
EVIDENCE FOR HYPOCHLOROUS ACID GENERATION
}

\author{
Stephen J. Weiss, Roger Klein, Adam Slivka, and Maria Wei, Department of \\ Internal Medicine, Simpson Research Institute, University of Michigan, Ann \\ Arbor, Michigan 48109
}

\begin{abstract}
A B S T R A C T The model hydrogen peroxide-myeloperoxidase-chloride system is capable of generating the powerful oxidant hypochlorous acid, which can be quantitated by trapping the generated species with the $\beta$-amino acid, taurine. The resultant stable product, taurine chloramine, can be quantitated by its ability to oxidize the sulfhydryl compound, 5-thio-2-nitrobenzoic acid to the disulfide, $5,5^{\prime}$-dithiobis(2-nitrobenzoic acid) or to oxidize iodide to iodine. Using this system, purified myeloperoxidase in the presence of chloride and taurine converted stoichiometric quantities of hydrogen peroxide to taurine chloramine. Chloramine generation was absolutely dependent on hydrogen peroxide, myeloperoxidase, and chloride and could be inhibited by catalase, myeloperoxidase inhibitors, or chloride-free conditions. In the presence of taurine, intact human neutrophils stimulated with either phorbol myristate acetate or opsonized zymosan particles generated a stable species capable of oxidizing 5-thio-2-nitrobenzoic acid or iodide. Resting cells did not form this species. The oxidant formed by the stimulated neutrophils was identified as taurine chloramine by both ultraviolet spectrophotometry and electrophoresis. Taurine chloramine formation by the neutrophil was dependent on the taurine concentration, time, and cell number. Neutrophil-dependent chloramine generation was inhibited by catalase, the myeloperoxidase inhibitors, azide, cyanide, or aminotriazole and by chloride-free conditions, but not by superoxide dismutase or hydroxyl radical scavengers. Thus, it appears that stimulated human neutrophils can utilize the hydrogen peroxide-myeloperoxidasechloride system to generate taurine chloramine. Based on the demonstrated ability of the myeloperoxidase
\end{abstract}

Drs. Klein, Slivka, and Wei completed this work in partial fulfillment of an Honors Degree from the University of Michigan.

Received for publication 18 January 1982 and in revised form 19 May 1982. system to generate free hypochlorous acid we conclude that neutrophils chlorinate taurine by producing this powerful oxidant. The biologic reactivity and cytotoxic potential of hypochlorous acid and its chloramine derivatives suggest that these oxidants play an important role in the inflammatory response and host defense.

\section{INTRODUCTION}

Human neutrophils can utilize the $\mathrm{H}_{2} \mathrm{O}_{2}$-myeloperoxidase-halide system to generate a powerful oxidant capable of destroying a variety of microorganisms and mammalian cell targets (1-4). Chloride, bromide, iodide, or thiocyanate may all be effective substrates in the myeloperoxidase system but, based on their in vivo concentrations, $\mathrm{Cl}^{-}$is thought to be the preferred halide $(1,4)$. In the presence of $\mathrm{Cl}^{-}$, the final mediator of myeloperoxidase-dependent events has been debated but increasing evidence indicates that hypochlorous acid $(\mathrm{HOCl})$ is the responsible toxic species (5-10). In 1976, Harrison and Schultz (10) demonstrated that a model system consisting of $\mathrm{H}_{2} \mathrm{O}_{2}$, purified myeloperoxidase, and $\mathrm{Cl}^{-}$generated $\mathrm{HOCl}$ (Eq. 1).

$$
\mathrm{H}_{2} \mathrm{O}_{2}+\mathrm{Cl}^{-} \underset{\mathrm{H}^{+}}{\stackrel{\text { myeloperoxidase }}{\rightleftarrows}} \mathrm{HOCl}+\mathrm{H}_{2} \mathrm{O} \text {. }
$$

Unlike other peroxidases that may oxidize acceptor molecules via the formation of a chlorinating intermediate (11), myeloperoxidase preferentially catalyzes the peroxidation of the chloride ion to free $\mathrm{HOCl}(10)$.

Recently, we have demonstrated that human neutrophils stimulated with phorbol myristate acetate (PMA) ${ }^{1}$ destroyed cell targets by a myeloperoxidasedependent process that could be inhibited by a variety of compounds known to scavenge $\mathrm{HOCl}(8,9)$. Al-

\footnotetext{
${ }^{1}$ Abbreviations used in this paper: DTNB, 5-5'-dithiobis(2-nitrobenzoic acid); PMA, phorbol myristate acetate; TNB, 5-thio-2-nitrobenzoic acid.
} 
though these data indicated that intact neutrophils have the potential to generate a species with characteristics similar, if not identical, with $\mathrm{HOCl}$, the rates and quantities of the chlorinating species produced are unknown. Attempts to directly measure the generation of chloride peroxidation products by intact cells are hampered by the short half-life of this oxidant in biological systems containing multiple potential substrates. To quantitatively detect chlorinating species generated by neutrophils, we have taken advantage of the ability of $\mathrm{HOCl}$ to rapidly react with the $\beta$ amino acid taurine to form the stable oxidant, taurine chloramine (12-14) (Eq. 2).

$\mathrm{HOCl}+\mathrm{H}_{2} \mathrm{~N}-\mathrm{CH}_{2} \mathrm{CH}_{2} \mathrm{SO}_{3} \mathrm{H} \rightarrow$

Taurine

$$
\mathrm{ClNH}-\mathrm{CH}_{2} \mathrm{CH}_{2} \mathrm{SO}_{3} \mathrm{H}+\mathrm{H}_{2} \mathrm{O}
$$

Taurine chloramine

In this manner we have examined the ability of intact, human neutrophils to utilize the $\mathrm{H}_{2} \mathrm{O}_{2}$-myeloperoxidase- $\mathrm{Cl}^{-}$system to generate a chloride peroxidation product capable of oxidizing taurine to its chloramine.

\section{METHODS}

Cell preparation. Neutrophils were obtained from the venous blood of healthy volunteers. Neutrophil preparations were isolated by Ficoll-Hypaque density centrifugation followed by dextran sedimentation (15). The preparations contained $>96 \%$ neutrophils and $2-3 \%$ eosinophils. Cells were suspended in Dulbecco's phosphate-buffered saline (Gibco Laboratories, Grand Island Biological Co., Grand Island, NY; pH 7.4 with $1 \mathrm{mg} / \mathrm{ml}$ glucose). In some experiments Dulbecco's buffer was replaced with a $0.1 \mathrm{M} \mathrm{NaCl}-0.029 \mathrm{M}$ sodium phosphate buffer with $1.5 \mathrm{~mm} \mathrm{MgSO}_{4}(\mathrm{pH} 7.4)$ or a halide-free $0.1 \mathrm{M}$ phosphate buffer with $1.5 \mathrm{mM} \mathrm{MgSO}_{4}(16)$.

\section{Assay systems}

Myeloperoxidase system. Varying concentrations of $\mathrm{H}_{2} \mathrm{O}_{2}$ were incubated alone or with purified myeloperoxidase in the presence or absence of taurine (Sigma Chemical Co., St. Louis, MO) in Dulbecco's buffer ( $\mathrm{pH}$ 7.4) in final volume of $1 \mathrm{ml}$ at $37^{\circ} \mathrm{C}$. In some experiments the Dulbecco's buffer was replaced with the chloride or chloride-free phosphate buffer. The $\mathrm{H}_{2} \mathrm{O}_{2}$ concentration was calculated from the absorbance at $230 \mathrm{~nm}$ assuming an extinction coefficient of 81 $\mathrm{M}^{-1} \mathrm{~cm}^{-1}$ (17). Purified canine myeloperoxidase was prepared (18) and kindly provided by Dr. J. Schultz (Papanicolaou Cancer Research Institute, Miami, FL). Myeloperoxidase activity was assayed by the $o$-dianisidine method (19) and activity expressed in international units. At the end of the incubation period, $50 \mu \mathrm{g}$ of catalase (type C-40, 12,000 $\mathrm{U} / \mathrm{mg}$, Sigma Chemical Co.) were added to reduce residual $\mathrm{H}_{2} \mathrm{O}_{2}$ and duplicate samples assayed for taurine chloramine formation.

Neutrophil system. Neutrophils were incubated with varying concentrations of taurine for indicated periods of time at $37^{\circ} \mathrm{C}$ in the described buffers $(\mathrm{pH} 7.4)$ in a final volume of $1 \mathrm{ml}$. Neutrophils were stimulated to generate oxygen metabolites and release lysosomal enzymes by the addition of PMA $(8,9)$ (Consolidated Midland Corp., Forrester, NY) or opsonized zymosan particles (Sigma Chemical Co.) prepared as previously described (15). At the end of the incubation period, catalase $(50 \mu \mathrm{g})$ was added and duplicate samples assayed for taurine chloramine formation as described below.

Other additions to the myeloperoxidase or neutrophil systems included bovine superoxide dismutase $(2,700 \mathrm{U} / \mathrm{mg}$, Sigma Chemical Co.), bovine catalase $(80,000 \mathrm{U} / \mathrm{mg}$, Worthington Biochemical Corp., Freehold, NJ), sodium azide, sodium cyanide (Fisher Scientific Co., Pittsburgh, PA), ethanol, mannitol or 3-amino-1,2,4-triazole (aminotriazole, Sigma Chemical Co.). Superoxide dismutase was assayed according to the method of McCord and Fridovich (20). Catalase was washed over an XM-100A ultrafiltration membrane (Amicon Corp., Lexington, MA) and assayed before use (19).

\section{Taurine chloramine quantitation}

The ability of $\mathrm{HOCl}$ to react with taurine was confirmed by adding a known amount of reagent $\mathrm{NaOCl}$ (Fisher Scientific Co.) to taurine. The $\mathrm{OCl}^{-}$concentration was calculated from its absorbance at $292 \mathrm{~nm}$ at $\mathrm{pH} 12.0$ assuming an extinction coefficient of $350 \mathrm{M}^{-1} \mathrm{~cm}^{-1}$ (21). Fig. 1 shows the UV spectrum of a solution of $\mathrm{OCl}^{-} / \mathrm{HOCl}\left(\mathrm{pK}_{\mathrm{a}} \sim 7.4\right)$

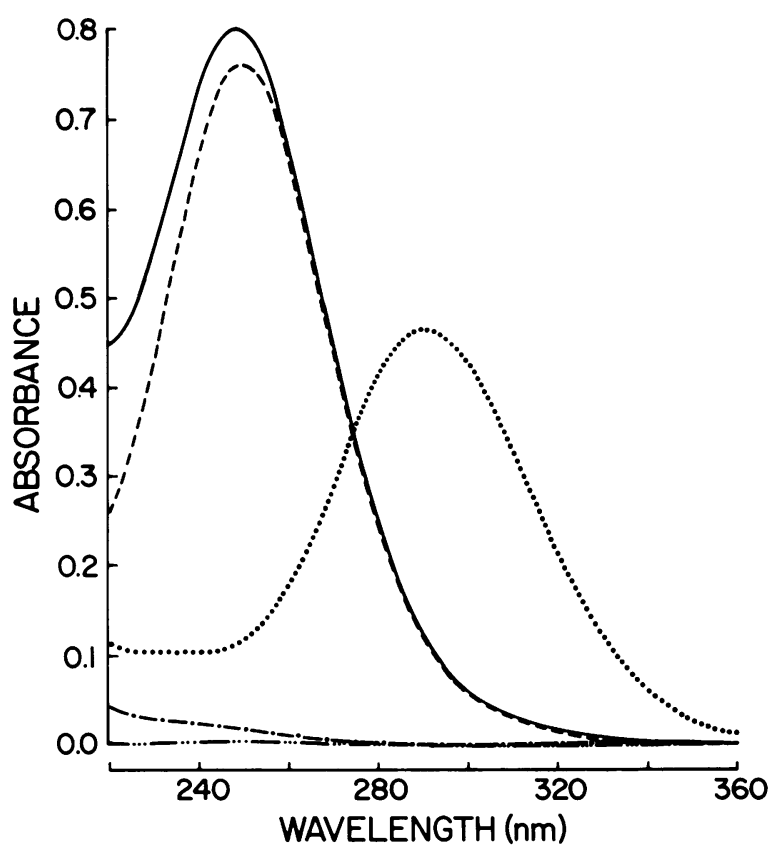

FIGURE 1 The UV absorption spectrum of synthesized taurine chloramine. Samples were incubated in Dulbecco's buffer ( $\mathrm{pH} \mathrm{7.4)}$ for $5 \mathrm{~min}$ at $25^{\circ} \mathrm{C}$ in a final volume of 1.5 $\mathrm{ml}$ and the spectra recorded. After the samples were scanned, $3.5 \mu \mathrm{mol}$ of $\mathrm{H}_{2} \mathrm{O}_{2}$ in a volume of $10 \mu \mathrm{l}$ were added to the $\mathrm{OCl}^{-} / \mathrm{HOCl}$ or the taurine- $\mathrm{OCl}^{-} / \mathrm{HOCl}$ mixtures, incubated for $5 \mathrm{~min}$ at $25^{\circ} \mathrm{C}$ and rescanned. (a) $15 \mu \mathrm{mol}$ of taurine alone $(-\cdots-)$; (b) $3.0 \mu \mathrm{mol}$ of a solution of $\mathrm{OCl}^{-} / \mathrm{HOCl}$ alone $(\cdots \cdots)$; (c) $15 \mu \mathrm{mol}$ of taurine and $3.0 \mu \mathrm{mol}$ of $\mathrm{OCl}^{-} /$ $\mathrm{HOCl}(----)$; (d) $\mathrm{OCl}^{-} / \mathrm{HOCl}$ plus $\mathrm{H}_{2} \mathrm{O}_{2}(-\cdot-\cdot-\cdot-) ;(e)$ taurine chloramine plus $\mathrm{H}_{2} \mathrm{O}_{2}(-)$. 
(21) in Dulbecco's buffer ( $\mathrm{pH}$ 7.4). Taurine does not absorb in this region. If a solution of $\mathrm{OCl}^{-} / \mathrm{HOCl}$ (referred to as $\mathrm{HOCl}$ ) was added to an excess of taurine a new compound was formed (Fig. 1). The resultant spectrum with a $\lambda$ maximum of $\sim 250 \mathrm{~nm}$ is characteristic of monochloramines (12, $13)$. Under these conditions, dichloramine formation ( $\lambda$ maximum $300 \mathrm{~nm}$ ) was not detected (14). To rule out the formation of a mixture of taurine chloramine and $\mathrm{HOCl}, \mathrm{H}_{2} \mathrm{O}_{2}$ was added to the system. $\mathrm{H}_{2} \mathrm{O}_{2}$ can reduce $\mathrm{HOCl}$ but does not react with taurine chloramine (7). As expected, the addition of $\mathrm{H}_{2} \mathrm{O}_{2}$ abolished the $\mathrm{HOCl}$ spectrum but had no effect on the taurine chloramine concentration (Fig. 1). The slight increase in the absorbance of the $\mathrm{H}_{2} \mathrm{O}_{2}-\mathrm{HOCl}$ or $\mathrm{H}_{2} \mathrm{O}_{2}$ taurine chloramine spectrum is due to the absorbance of $\mathrm{H}_{2} \mathrm{O}_{2}$ alone. The taurine chloramine spectrum did not change after a 4-h incubation at $37^{\circ} \mathrm{C}$. Thus, under our conditions, $\mathrm{HOCl}$ can react with taurine to form the stable chloramine. Although taurine chloramine can be quantitated directly by its absorbance at $250 \mathrm{~nm}$, the system is not sufficiently sensitive for the neutrophil studies because of the low extinction coefficient of chloramine $\left(\sim 398 \mathrm{M}^{-1}\right.$ $\mathrm{cm}^{-1}$ ) (14).

Because $1 \mathrm{~mol}$ taurine chloramine retains $2 \mathrm{~mol}$ oxidizing equivalents (7), its concentration can be sensitively determined by the ability to oxidize 2 mol of the sulfhydryl compound 5-thio-2-nitrobenzoic acid (TNB) to $1 \mathrm{~mol}$ of the disulfide, 5-5'-dithiobis(2-nitrobenzoic acid) (DTNB) or $2 \mathrm{~mol}$ of $\mathrm{I}^{-}$to $\mathrm{I}_{2}(7,14)$. TNB was prepared by reducing DTNB (Sigma Chemical Co.) (7) and its concentration determined by its absorbance at $412 \mathrm{~nm}$ assuming an extinction coefficient of $1.36 \times 10^{4} \mathrm{M}^{-1} \mathrm{~cm}^{-1}(22)$. The $I_{2}$ concentration was determined spectrophotometrically in the presence of excess $\mathrm{I}^{-}$as $\mathrm{I}_{3}^{-}\left(\epsilon=2.29 \times 10^{4} \mathrm{M}^{-1} \mathrm{~cm}^{-1}\right)(23)$.

In experiments with the model myeloperoxidase system or intact neutrophils, samples were assayed for taurine chloramine formation at the end of the incubation period by adding either TNB $(0.45 \mathrm{mM})$ or $\mathrm{KI}(20 \mathrm{mM})$ to the entire mixture. The samples were immediately centrifuged (500 $g$ for $5 \mathrm{~min}$ ) and the absorbance recorded at 412 or $350 \mathrm{~nm}$, respectively. In selected neutrophil experiments, the supernatant and cell button were analyzed separately for chloramine content. Catalase was added to all systems before the addition of TNB or KI due to the ability of high concentrations of $\mathrm{H}_{2} \mathrm{O}_{2}$ to slowly oxidize TNB or $\mathrm{I}^{-}$. The addition of catalase did not interfere with either of the assays.

\section{High voltage paper electrophoresis}

In selected experiments the presence of taurine chloramine formation was examined by high voltage paper electrophoresis. Supernates were removed from the test mixtures and spotted on Whatman No. 3MM paper (Whatman Ltd. England). Electrophoresis runs were carried out for $30 \mathrm{~min}$ in a borate buffer (pH 9.0) at 3,000 V and a current of 150 mA. Taurine was visualized with ninhydrin spray (Sigma Chemical Co.) and the taurine chloramine was visualized with a $2 \% \mathrm{KI}$ solution in acetone (13).

\section{Hydrogen peroxide generation}

$\mathrm{H}_{2} \mathrm{O}_{2}$ generation was determined in the presence of $1 \mathrm{mM}$ azide by the method of Thurman et al. (24).

\section{RESULTS}

Taurine chloramine generation by the $\mathrm{H}_{2} \mathrm{O}_{2}$-myeloperoxidase- $\mathrm{Cl}^{-}$system. Under ideal conditions, the addition of known amounts of $\mathrm{H}_{2} \mathrm{O}_{2}$ to purified myeloperoxidase and $\mathrm{Cl}^{-}$should result in the formation of an equimolar concentration of $\mathrm{HOCl}$. If the experiment is performed in the presence of an excess of taurine, then the HOCl should be trapped as the chloramine. Fig. 2 illustrates the relationship between $\mathrm{H}_{2} \mathrm{O}_{2}$ added and taurine chloramine detected in a cellfree myeloperoxidase system. Under the conditions used, $\sim 100 \%$ of the $\mathrm{H}_{2} \mathrm{O}_{2}$ was converted to chloramine. The presence of taurine chloramine was confirmed by the UV absorption spectrum of the sample. As described in Methods, the chloramine had an absorption maximum at $\sim 250 \mathrm{~nm}$ and was resistant to $\mathrm{H}_{2} \mathrm{O}_{2}$ (data not shown). The amount of taurine chloramine formed was also dependent on the taurine concentration. As little as $0.1 \mathrm{mM}$ taurine $(100 \mathrm{nmol} / \mathrm{ml})$ scavenged almost all of the $\mathrm{HOCl}$ (data not shown) If $100 \mathrm{nmol}$ of $\mathrm{H}_{2} \mathrm{O}_{2}$ were added to myeloperoxidase and $\mathrm{Cl}^{-}$in the absence of taurine, incubated for 60 min and then taurine added, $<5 \mathrm{nmol}$ of chloramine could be detected. Although the enzyme does not require taurine to generate $\mathrm{HOCl}$, myeloperoxidase is rapidly inactivated by this oxidant $(6,10)$ and any residual $\mathrm{HOCl}$ would be reduced by $\mathrm{H}_{2} \mathrm{O}_{2}$ (7). Thus, it appears that the myeloperoxidase system can utilize $\mathrm{H}_{2} \mathrm{O}_{2}$ to generate $\mathrm{HOCl}$ which, in the presence of taurine, leads to the formation of chloramine.

Requirements for taurine chloramine formation by the model myeloperoxidase system. Elimination of $\mathrm{H}_{2} \mathrm{O}_{2}$, myeloperoxidase, or $\mathrm{Cl}^{-}$completely inhibited the formation of taurine chloramine (Table I). As ex-

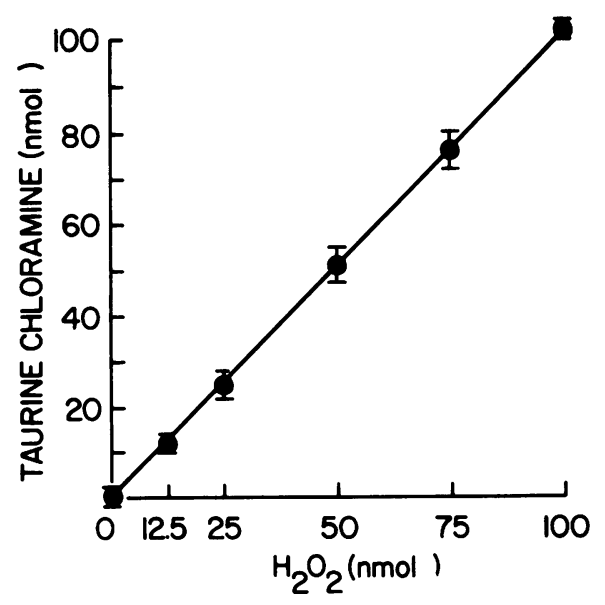

Figure 2 The formation of taurine chloramine by a model $\mathrm{H}_{2} \mathrm{O}_{2}$-myeloperoxidase- $\mathrm{Cl}^{-}$system. Known amounts of $\mathrm{H}_{2} \mathrm{O}_{2}$ were added to $16 \mathrm{mU}$ of purified myeloperoxidase in Dulbecco's buffer ( $\mathrm{pH} \mathrm{7.4)}$ in a final volume of $1 \mathrm{ml}$ in the presence of $5 \mathrm{mM}$ taurine. Samples were incubated for 60 min at $37^{\circ} \mathrm{C}$ and assayed by the TNB method. Results are expressed as the mean \pm 1 SD of four experiments. 
TABLE I

Taurine Chloramine Generation by the $\mathrm{H}_{2} \mathrm{O}_{2}$ Myeloperoxidase- $\mathrm{Cl}^{-}$System

\begin{tabular}{|c|c|}
\hline Additive ${ }^{\bullet}$ & $\begin{array}{l}\text { Taurine chloramine } \\
\text { formed }\end{array}$ \\
\hline & nmolt \\
\hline $\mathrm{H}_{2} \mathrm{O}_{2}+\mathrm{Cl}^{-}$ & $0.0 \pm 0.0$ \\
\hline $\mathrm{H}_{2} \mathrm{O}_{2}+$ myeloperoxidase $\left(\mathrm{Cl}^{-}\right.$free $)$ & $0.0 \pm 0.0$ \\
\hline Complete system & $102.8 \pm 1.4$ \\
\hline Complete system + catalase $(50 \mu \mathrm{g} / \mathrm{ml})$ & $4.6 \pm 2.1$ \\
\hline $\begin{array}{l}\text { Complete system }+ \text { heat-inactivated } \\
\text { catalase }(50 \mu \mathrm{g} / \mathrm{ml})\end{array}$ & $101.8 \pm 1.2$ \\
\hline $\begin{array}{l}\text { Complete system + superoxide dismutase } \\
(10 \mu \mathrm{g} / \mathrm{ml})\end{array}$ & $101.3 \pm 1.5$ \\
\hline Complete system + azide $(1 \mathrm{mM})$ & $2.7 \pm 0.6$ \\
\hline Complete system + cyanide (1 mM) & $5.0 \pm 1.6$ \\
\hline Complete system + aminotriazole $(10 \mathrm{mM})$ & $0.0 \pm 0.0$ \\
\hline Complete system + ethanol (40 mM) & $100.9 \pm 2.7$ \\
\hline Complete system + mannitol (40 mM) & $99.0 \pm 4.6$ \\
\hline
\end{tabular}

- The complete system consisted of $100 \mathrm{nmol} \mathrm{H}_{2} \mathrm{O}_{2}, 16 \mathrm{mU}$ of myeloperoxidase, and $5 \mathrm{mM}$ taurine incubated for $60 \mathrm{~min}$ in Dulbecco's phosphate-buffered saline at $37^{\circ} \mathrm{C}$ in a final volume of 1 $\mathrm{ml}$. In the $\mathrm{Cl}^{-}$free experiments a $0.1 \mathrm{M}$ phosphate buffer was used. The $0.1 \mathrm{M} \mathrm{NaCl}$-phosphate buffer gave results identical to those obtained with the Dulbecco's buffer.

$\downarrow$ The taurine chloramine concentration was determined as described by the TNB method. Results are expressed at the mean \pm 1 SD of four experiments.

pected, the addition of catalase (degrades $\mathrm{H}_{2} \mathrm{O}_{2}$ ) markedly inhibited chloramine formation, while neither superoxide dismutase (dismutates $\mathrm{O}_{2}{ }^{--}$to $\mathrm{H}_{2} \mathrm{O}_{2}$ ) nor heat-inactivated catalase had any effect (Table 1). Azide, cyanide, and aminotriazole, three classic myeloperoxidase inhibitors, all blocked taurine chloramine formation, and the $\mathrm{OH}^{*}$ scavengers, ethanol or mannitol, were without an inhibitory effect. Thus, as predicted, taurine chloramine formation was dependent on $\mathrm{H}_{2} \mathrm{O}_{2}$, functional myeloperoxidase, and $\mathrm{Cl}^{-}$.

Taurine chloramine formation by intact neutrophils. If intact neutrophils can utilize the $\mathrm{H}_{2} \mathrm{O}_{2}$-myeloperoxidase $-\mathrm{Cl}^{-}$system to generate $\mathrm{HOCl}$ or a species of similar reactivity we would predict that, in the presence of taurine, stimulated neutrophils should produce taurine chloramine. Fig. 3 demonstrates that a mixture of $2.5 \times 10^{6}$ PMA-stimulated neutrophils incubated with taurine for $2 \mathrm{~h}$ accumulated a species capable of oxidizing TNB to DTNB. Resting cells did not oxidize any of the TNB added. Addition of a reducing agent (cysteine) resulted in the recovery of $>98 \%$ of the added TNB. The presence of taurine chloramine was confirmed in scaled up experiments by UV spectrophotometry. Fig. 4 illustrates the typical absorption maximum of taurine chloramine in the supernatant of

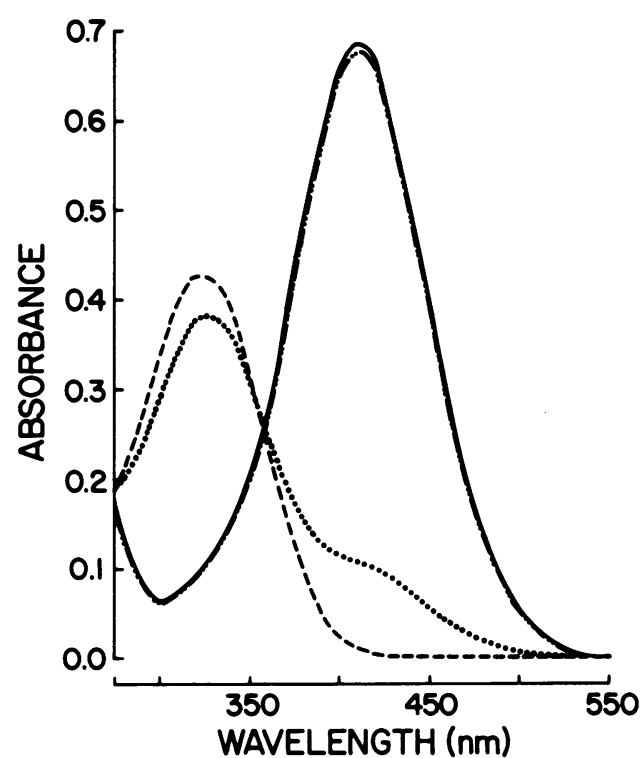

Figure 3 Optical spectra of TNB oxidized by PMA-stimulated neutrophils in the presence of taurine. $2.5 \times 10^{6} \mathrm{PMA}-$ stimulated neutrophils were incubated with $15 \mathrm{mM}$ taurine

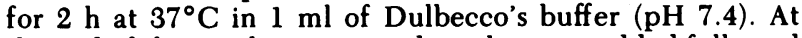
the end of the incubation period catalase was added followed by TNB (450 $\mathrm{nmol})$. The mixture was centrifuged, diluted, and immediately scanned. After the spectrum was recorded, a small amount of solid cysteine was added (to reduce DTNB to TNB) and the sample scanned. (a) $225 \mathrm{nmol}$ to DTNB diluted as above, $\lambda$ maximum $\sim 325 \mathrm{~nm}(----)$; (b) $450 \mathrm{nmol}$ of TNB, $\lambda$ maximum $412 \mathrm{~nm}(-)$; (c) $450 \mathrm{nmol}$ of TNB incubated with cell mixture $(\cdots \cdots) ;(d)$ TNB-cell mixture

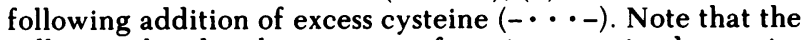
cells stimulated in the presence of taurine contained a species that decreased the absorption peak of the TNB at $412 \mathrm{~nm}$ and increased the absorption peak at $325 \mathrm{~nm}$ suggesting a mixture of DTNB and TNB. The addition of cysteine to this mixture ablated the $325-\mathrm{nm}$ peak and regenerated the 412 $\mathrm{nm}$ maximum.

$20 \times 10^{6}$ PMA-stimulated neutrophils after a 2-h incubation in the presence of taurine. No peak was observed in this region with resting cells (Fig. 4). As expected, the addition of $\mathrm{H}_{2} \mathrm{O}_{2}$ did not reduce the chloramine (data not shown). Identical results were obtained with opsonized zymosan-stimulated neutrophils. The presence of taurine chloramine was also reinforced by high voltage paper electrophoresis. In this system, taurine standards migrated $5.5 \mathrm{~cm}$, while synthesized taurine chloramine migrated $17.0 \mathrm{~cm}$ (toward the anode), and could be visualized by its ability to oxidize $\mathrm{I}^{-}$to $\mathrm{I}_{2}$. Electrophoresis of supernates obtained from PMA- or zymosan-stimulated neutrophils revealed an $\mathrm{I}^{-}$reactive material that comigrated with synthesized taurine chloramine (i.e., $17 \mathrm{~cm}$ toward the anode). Thus, we conclude that intact, stimulated neutrophils can generate taurine chloramine. 


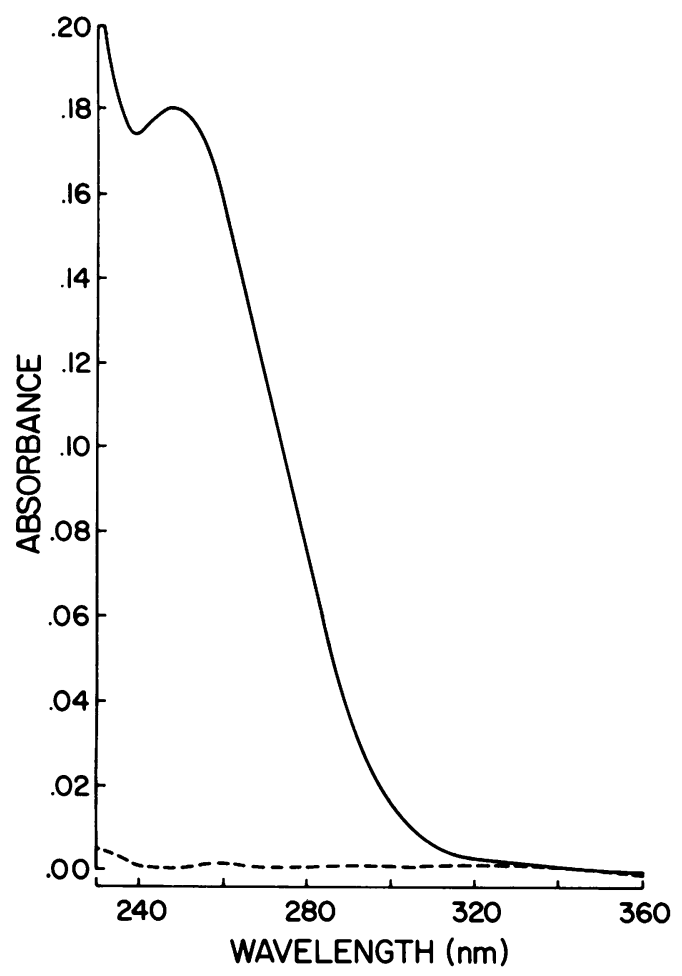

Figure 4 Optical spectra of oxidant generated by PMAstimulated neutrophils in the presence of taurine. $20 \times 10^{6}$ neutrophils were incubated with or without $15 \mathrm{mM}$ taurine in the presence or absence of PMA $(100 \mathrm{ng} / \mathrm{ml})$ for $2 \mathrm{~h}$ at $37^{\circ} \mathrm{C}$ in $2 \mathrm{ml}$ of Dulbecco's buffer ( $\mathrm{pH} \mathrm{7.4)}$. At the end of the incubation period the samples were centrifuged, diluted, and scanned. The reference cuvettes contained resting or stimulated cells in the absence of taurine. (a) Resting cells vs. resting cells with taurine (--.--) and (b) stimulated cells vs. stimulated cells with taurine (-). Stimulated cells released material that absorbed strongly below $240 \mathrm{~nm}$ masking the descending shoulder of the chloramine.

Quantitation of taurine chloramine generation by neutrophils. Both PMA- or zymosan-stimulated neutrophils generated increasing amounts of taurine chloramine as the taurine concentration was increased until a plateau was reached at $\sim 15 \mathrm{mM}$ taurine (Fig. 5). The dose of PMA $(30 \mathrm{ng} / \mathrm{ml})$ and zymosan $(1.25 \mathrm{mg} /$ $\mathrm{ml})$ used gave maximal results. Resting cells did not generate detectable amounts of taurine chloramine. In addition, $15 \mathrm{mM}$ taurine did not depress the neutrophils' respiratory burst as assessed by $\mathrm{O}_{2}$ consumption, $\mathrm{O}_{2}{ }^{--}$generation (data not shown), or by $\mathrm{H}_{2} \mathrm{O}_{2}$ release from azide. $2.5 \times 10^{5} \mathrm{PMA}$ - or zymosan-stimulated neutrophils in the presence of $1 \mathrm{mM}$ azide generated $39.7 \pm 4.6$ and $32.0 \pm 8.3 \mathrm{nmol} \mathrm{H}_{2} \mathrm{O}_{2} / \mathrm{h}$ alone while producing $43.0 \pm 3.7$ and $32.0 \pm 10.0 \mathrm{nmol} / \mathrm{h}$, respectively, in the presence of $15 \mathrm{mM}$ taurine (mean \pm 1 $\mathrm{SD}, n=3$ ).

Taurine chloramine generation was dependent on the length of the incubation period and was essentially complete after a 2 -h incubation (Fig. 6A). The relationship between neutrophils number and taurine chloramine formation is illustrated in Fig. 6B. In 15 experiments $2 \times 10^{6} \mathrm{PMA}$-stimulated neutrophils generated $126.4 \pm 13.0 \mathrm{nmol}$ chloramine during a 2 -h incubation, while zymosan-stimulated cells produced 108.0 \pm 11.1 (mean \pm 1 SD). In three paired experiments, chloramine concentrations determined by the TNB method varied $<5 \%$ from those obtained with the KI technique. PMA-stimulated cells generated $129.7 \pm 11.1 \mathrm{nmol}$ of taurine chloramine by the TNB method and $123.5 \pm 9.7 \mathrm{nmol}$ with the $\mathrm{KI}$ method, while zymosan-stimulated cells formed 119.1 \pm 8.5 $\mathrm{nmol}$ and $116.7 \pm 8.7 \mathrm{nmol}$ by the TNB and KI methods, respectively. Although chloramine determinations were routinely made on the entire incubation mixture, separate analysis of the supernatant and the cell button revealed that $\sim 10 \%$ of the oxidant remained associated with the neutrophil.

These results indicate that neutrophils can produce significant amounts of taurine chloramine, but the quantitation assumes that the generated chloramine is stable in the complex cell system. To assess the stability of taurine chloramine in the neutrophil system, we examined our ability to recover $50 \mathrm{nmol}$ of exogenous taurine chloramine from mixtures of both resting and PMA- or zymosan-stimulated cells. After a 2$h$ incubation, $>95 \%$ of the exogenous taurine chloramine could be recovered from either the resting or stimulated cell mixtures. Thus, this quantitative technique appears to accurately reflect the total amount of taurine chloramine generated.

Requirements for taurine chloramine formation by neutrophils. If taurine chloramine generation by the stimulated neutrophil is mediated by $\mathrm{HOCl}$ or a similar species, we would expect a requirement for $\mathrm{H}_{2} \mathrm{O}_{2}$, myeloperoxidase, and $\mathrm{Cl}^{-}$. As shown in Table II, catalase significantly inhibited taurine chloramine generation by $2 \times 10^{6}$ PMA- or zymosan-stimulated neutrophils. The inhibitory effect of catalase increased to 90 and $65 \%$ with $1 \times 10^{6}$ PMA- or zymosan-stimulated cells, respectively (PMA control $53.8 \pm 9.3 ; n=5$, zymosan control $53.7 \pm 10.4 ; n=3)$. Heat-inactivated catalase had no inhibitory effect with either stimulus (Table II). The addition of superoxide dismutase did not inhibit chloramine generation by the neutrophils with either stimulus. The heme-enzyme inhibitors, azide, cyanide, and aminotriazole were each capable of inhibiting chloramine formation, while neither ethanol nor mannitol had any inhibitory effect (Table II).

Because endogenous myeloperoxidase was apparently required for chloramine formation, we examined the effect of exogenous peroxidase in the neutrophil 


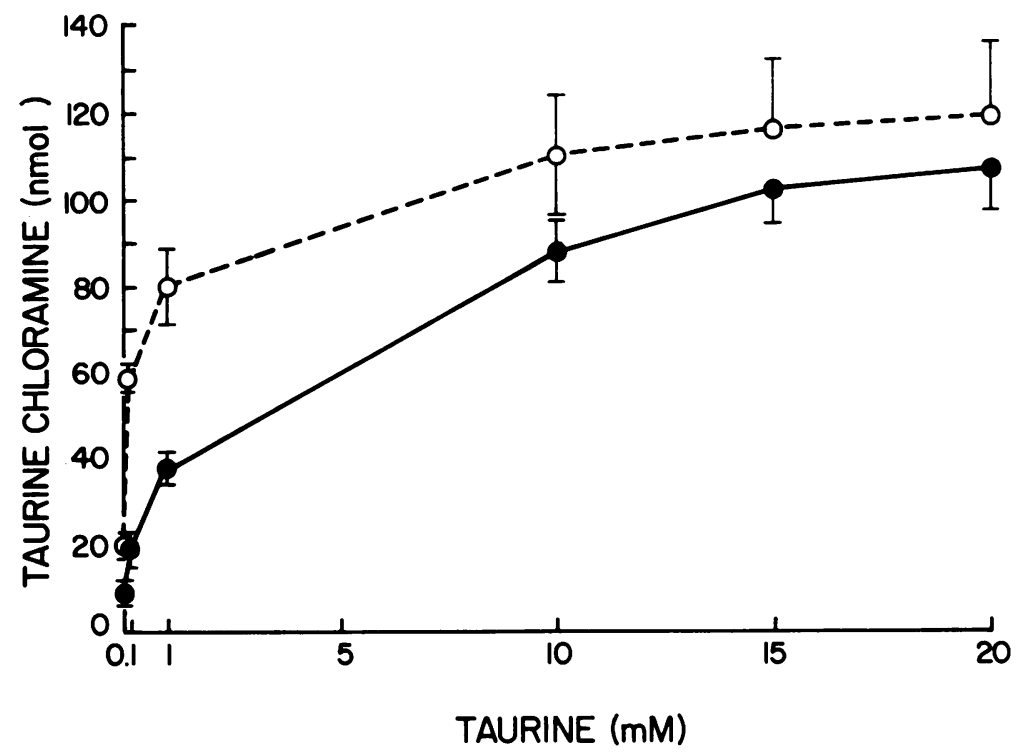

Figure 5 The effect of taurine concentration on the formation of taurine chloramine by neutrophils. $2 \times 10^{6}$ neutrophils were incubated with varying concentrations of taurine for 2 $\mathrm{h}$ at $37^{\circ} \mathrm{C}$ in $1 \mathrm{ml}$ of Dulbecco's buffer (pH 7.4). Neutrophils were incubated in the presence of $30 \mathrm{ng} / \mathrm{ml}$ of PMA (- $\left.\mathrm{O}_{-} \mathrm{O}_{-}\right)$or $1.25 \mathrm{mg} / \mathrm{ml}$ of opsonized zymosan (- - - - Taurine formation was quantitated by the TNB method. Results are expressed as the mean \pm SD of three experiments.

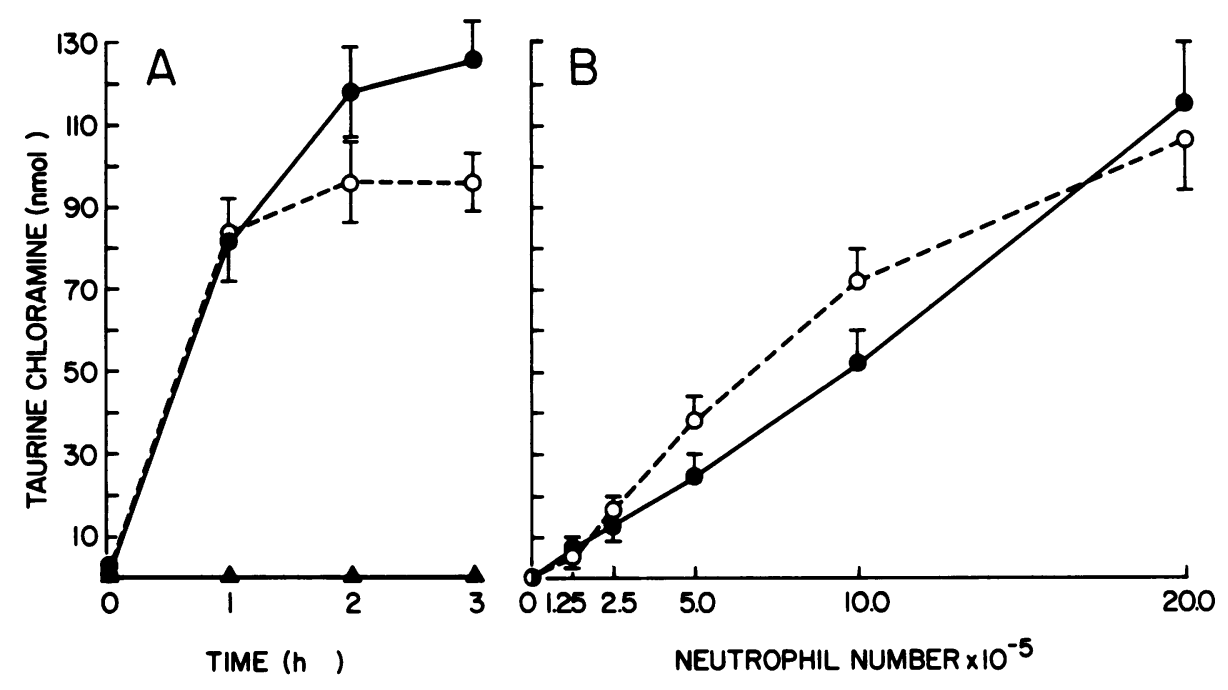

Figure 6(A) Taurine chloramine formation by neutrophils as a function of time. $2 \times 10^{6}$ neutrophils were incubated with $15 \mathrm{mM}$ taurine for varying periods of time at $37^{\circ} \mathrm{C}$ in $1 \mathrm{ml}$ of Dulbecco's buffer ( $\mathrm{pH}$ 7.4). Neutrophils were incubated in the absence of a stimulus $(-\Delta-\Delta-)$ and in the presence of $30 \mathrm{ng} / \mathrm{ml}$ of PMA $(-\cdot--)$ or $1.25 \mathrm{mg} / \mathrm{ml}$ of opsonized zymosan (-O-O-). Taurine chloramine formation was quantitated by the TNB method. Results are expressed as the mean \pm 1 SD of five experiments. (B) Taurine chloramine formation as a function of neutrophils number. Varying numbers of neutrophils were incubated with 15 $\mathrm{mM}$ taurine for $2 \mathrm{~h}$ at $37^{\circ} \mathrm{C}$ in $1 \mathrm{ml}$ of Dulbecco's buffer (pH 7.4). Neutrophils were stimulated with either $30 \mathrm{ng} / \mathrm{ml}$ of PMA (-•---) or $1.25 \mathrm{mg} / \mathrm{ml}$ of opsonized zymosan particles (-O-O-). Taurine chloramine formation was quantitated by the TNB method. Results are expressed as the mean $\pm 1 \mathrm{SD}$ of five experiments. 
TABLE II

Characteristics of Taurine Chloramine Generation by Neutrophils

\begin{tabular}{lcc}
\hline & \multicolumn{2}{c}{ Percentage of controlt } \\
\cline { 2 - 3 } \multicolumn{1}{c}{ Additive } & PMA & Zymosan \\
\hline & & \\
Catalase $(40 \mu \mathrm{g} / \mathrm{ml})$ & $16.7 \pm 2.7$ & $51.2 \pm 3.8$ \\
Heat-inactivated catalase & & \\
$\quad(40 \mu \mathrm{g} / \mathrm{ml})$ & 100.0 & 96.5 \\
Superoxide dismutase $(10$ & & \\
$\quad \mu \mathrm{g} / \mathrm{ml})$ & $105.8 \pm 3.4$ & $113.6 \pm 11.7$ \\
Azide $(0.1 \mathrm{mM})$ & $3.4 \pm 4.4$ & $2.6 \pm 4.2$ \\
Azide $(10 \mu \mathrm{M})$ & $3.0 \pm 3.6$ & $6.3 \pm 4.0$ \\
Azide $(1 \mu \mathrm{M})$ & $37.7 \pm 1.5$ & $76.4 \pm 7.5$ \\
Azide $(0.1 \mu \mathrm{M})$ & $87.7 \pm 5.9$ & $97.3 \pm 3.1$ \\
Cyanide $(0.5 \mathrm{mM})$ & $1.2 \pm 1.1$ & $3.4 \pm 4.8$ \\
Cyanide $(0.1 \mathrm{mM})$ & $20.3 \pm 6.7$ & $33.7 \pm 4.5$ \\
Cyanide $(10 \mu \mathrm{M})$ & $95.3 \pm 4.2$ & $98.0 \pm 3.5$ \\
Aminotriazole & & \\
$\quad(10.0 \mathrm{mM})$ & $0.0 \pm 0.0$ & $2.8 \pm 3.4$ \\
Ethanol $(40 \mathrm{mM})$ & $106.1 \pm 4.8$ & $93.4 \pm 4.0$ \\
Mannitol $(40 \mathrm{mM})$ & $103.9 \pm 7.2$ & $105.4 \pm 5.0$ \\
Chloride-free system & 8.0 & 8.7 \\
Chloride-free $+\mathrm{H}_{2} \mathrm{O}_{2}$ & & \\
$\quad(100 \mathrm{nmol})$ & 8.4 & 7.2 \\
Chloride-free & & \\
$\quad+$ myeloperoxidase & 10.0 & 3.5 \\
$\quad(16 \mathrm{mU})$ & & \\
Chloride-free $+\mathrm{H}_{2} \mathrm{O}_{2}$ & & \\
$\quad+$ myeloperoxidase & & \\
\hline & & \\
\hline
\end{tabular}

- The complete system consisted of $2 \times 10^{6}$ neutrophils incubated with $15 \mathrm{mM}$ taurine in Dulbecco's buffer (pH 7.4) in a final volume of $1 \mathrm{ml}$ at $37^{\circ} \mathrm{C}$ for $2 \mathrm{~h}$. The cells were stimulated with either PMA $(30 \mathrm{ng} / \mathrm{ml})$ or zymosan $(1.25 \mathrm{mg} / \mathrm{ml})$. Neutrophils were preincubated with azide, cyanide, or aminotriazole for $5 \mathrm{~min}$ at room temperature before addition of the stimulus. The chloride-free experiments were performed in the $0.1 \mathrm{M}$ sodium phosphate buffer with $\mathrm{MgSO}_{4}$ (pH 7.4).

$\downarrow$ Results are expressed as the mean percentage of control \pm 1 SD of six paired experiments with catalase, superoxide dismutase, azide, cyanide and aminotriazole. Heat-inactivated catalase was studied in two-paired experiments. The control taurine chloramine generation for PMA- and zymosan-stimulated cells were 115.1 \pm 15.3 and $98.2 \pm 20.4$, respectively. The results for the $\mathrm{Cl}-$ free experiments are expressed as the mean of two-paired experiments. The controls were performed in a $0.1 \mathrm{M} \mathrm{NaCl}$-phosphate buffer and the values for $2 \times 10^{6}$ PMA- and zymosan-stimulated neutrophils were 122.0 and $85.5 \mathrm{nmol}$ taurine chloramine, respectively.

$\$$ If the azide concentration was increased to $1 \mathrm{mM}$, the TNB oxidation was inhibited only $50 \%$. Further studies revealed that in the presence of $1 \mathrm{mM}$ azide, high concentrations of $\mathrm{H}_{2} \mathrm{O}_{2}$ were formed capable of mediating TNB or $1^{-}$oxidation. In contrast, higher concentrations of cyanide did not increase TNB oxidation. However, cyanide along with other nucleophiles can directly reduce DTNB (25). In this system the addition of $\leq 1 \mathrm{mM}$ cyanide reduced $<5 \mathrm{nmol}$ of DTNB. system. PMA is a poor stimulus for myeloperoxidase release $(26,27)$ and exogenous enzyme might be expected to enhance chloramine generation. Indeed, in three experiments the addition of $16 \mathrm{mU}$ of purified myeloperoxidase enhanced chloramine generation by $2 \times 10^{6}$ PMA-stimulated neutrophils from $124.0 \pm 8.0$ $\mathrm{nmol}$ to $178.0 \pm 4.0 \mathrm{nmol}$ during a 2 -h incubation. $\mathrm{Zy}$ mosan-stimulated neutrophils were not affected by the addition of myeloperoxidase (119.1 \pm 3.5 vs. $116.7 \pm 3.7$ nmol taurine chloramine; $n=3$ ).

A possible requirement for $\mathrm{Cl}^{-}$was examined by performing the neutrophil experiments in a $\mathrm{Cl}^{-}$-free buffer (Table II). In the absence of $\mathrm{Cl}^{-}$chloramine generation was significantly inhibited. Although the functional activity of the neutrophil in a $\mathrm{Cl}^{-}$-free system is questionable, neither the addition of exogenous $\mathrm{H}_{2} \mathrm{O}_{2}$ nor myeloperoxidase alone or in combination stimulated chloramine generation. Thus, it appears that both PMA- or zymosan-stimulated neutrophils utilize the $\mathrm{H}_{2} \mathrm{O}_{2}$-myeloperoxidase- $\mathrm{Cl}^{-}$system to generate taurine chloramine.

\section{DISCUSSION}

Neutrophils can generate $\mathrm{H}_{2} \mathrm{O}_{2}$ and release myeloperoxidase into a $\mathrm{Cl}^{-}$containing environment to form a powerful oxidizing agent capable of attacking microorganisms, mammalian cells $(1,4)$, and a variety of soluble inflammatory mediators (for recent examples, see references 28 and 29). In the presence of $\mathrm{H}_{2} \mathrm{O}_{2}$ and $\mathrm{Cl}^{-}$, purified myeloperoxidase can continuously generate free $\mathrm{HOCl}$ via a mechanism that does not require the presence of organic chloride acceptors (10). Apparently, the enzyme system does not directly chlorinate substrates nor does it generate other chloride oxidation products. In solution, $\mathrm{HOCl}$ may be in equilibrium with other oxychloro compounds, but $\mathrm{HOCl}$ and its anion $\mathrm{OCl}^{-}$are the predominant species under physiologic conditions (30).

Both $\mathrm{HOCl}$ and $\mathrm{OCl}^{-}$are powerful oxidants capable of reacting with amines, amino acids, sulfhydryls, disulfides, thioethers, aromatics, and a variety of potentially important biological substrates (30-32). Because of this reactivity, steady-state concentrations of $\mathrm{HOCl}$ and $\mathrm{OCl}^{-}$would be difficult to detect in complex biological systems. In this study, we chose taurine as a model compound capable of reacting with $\mathrm{HOCl} /$ $\mathrm{OCl}^{-}$at diffusion controlled rates to form a stable and quantitable chloramine derivative (12-14). The applicability of this technique was initially examined in a model $\mathrm{H}_{2} \mathrm{O}_{2}$-myeloperoxidase- $\mathrm{Cl}^{-}$system wherein $\mathrm{H}_{2} \mathrm{O}_{2}$ was stoichiometrically oxidized to a product capable of chlorinating taurine. Based on the known ability of the myeloperoxidase system to generate free 
HOCl (10), it would seem that this oxidant was responsible for taurine chloramine formation. Thus, it appeared that taurine might allow us to trap and quantitate chloride peroxidation products generated by the intact neutrophil.

In the presence of taurine, PMA- or zymosan-stimulated neutrophils generated large quantities of a species capable of oxidizing TNB to DTNB or $\mathrm{I}^{-}$to $\mathrm{I}_{2}$. Both UV spectrophotometry and high voltage paper electrophoresis helped confirm the formation of taurine chloramine. Although monochloramines can be oxidized to dichloramines $(13,14,30)$, we found no evidence for the generation of this oxidant by the neutrophil in the presence of a large excess of taurine. These data indicate that neutrophils can form an oxidant capable of attacking the amine group of taurine to form the $\mathrm{N}-\mathrm{Cl}$ derivative.

Chloramine generation by the neutrophils plateaued as the concentration of exogenous taurine reached 15 $\mathrm{mM}$. The optimal concentration of taurine was significantly higher than that used in the model myeloperoxidase system and probably reflects the increased number of potential substrates in the more complex neutrophil system. Similarly, at low taurine concentrations, increased amounts of chloramine were detected with PMA as the stimulant as opposed to zymosan particles. Higher concentrations of taurine might be required to scavenge the oxidant with zymosan because the chloride peroxidation product can react with the opsonized particle. ${ }^{2}$ Alternatively, zymosan is internalized and high taurine concentrations could favor an increased intravacuolar concentration of the scavenger. It is interesting to note that even in the absence of exogenous taurine, small amounts of a stable oxidant could be detected with either stimulant (Fig. 5). Whether this represents the formation of an endogenous chloramine or some other stable oxidant remains to be determined.

Analysis of the oxidant distribution in the supernatant and cell button revealed that the majority of the chloramine was in the extracellular milieu, but we cannot be certain that this necessarily reflects extracellular chloramine generation. Either the chloride peroxidation products or the chloramine itself might be generated within the vacuole and then diffuse out of the cell. At present, the amounts of taurine available within the vacuolar space to scavenge the oxidant are unknown. Alternatively, neutrophils do release $\mathrm{H}_{2} \mathrm{O}_{2}$ and myeloperoxidase extracellularly $(1,4)$, and we might be detecting only those chloramines generated outside the cell. In other studies, myeloperoxidase-

${ }^{2}$ S. J. Weiss. Unpublished observations. mediated iodination products generated by neutrophils are also preferentially localized in the extracellular rather than the intracellular environment $(1,16)$.

Studies designed to determine the requirements for taurine chloramine generation by the neutrophil clearly indicated a pivotal role for $\mathrm{H}_{2} \mathrm{O}_{2}$, myeloperoxidase, and $\mathrm{Cl}^{-}$. First, the ability of the cell to generate the chloramine was inhibited in the presence of catalase. Although catalase inhibited taurine chloramine generation by either PMA- or zymosan-stimulated cells, it was more effective in the PMA system. PMA-stimulated cells release large amounts of oxygen metabolites extracellularly but only small quantities of myeloperoxidase $(26,27)$, while zymosan-stimulated neutrophils generate oxygen metabolites and release large amounts of myeloperoxidase into the phagocytic vacuole. Thus, in the presence of PMA, catalase may not have to gain access into the small vacuolar space to inhibit chloramine formation and, in addition, would be competing for $\mathrm{H}_{2} \mathrm{O}_{2}$ with a lower concentration of myeloperoxidase. Second, a role for myeloperoxidase was underlined by the ability of azide, cyanide, and aminotriazole to inhibit taurine chloramine generation. Although cyanide and aminotriazole can directly inhibit myeloperoxidase, they can also react with $\mathrm{HOCl}(30)$. It should be noted that a variety of peroxidase inhibitors seem to mediate their effects by interacting with the activated halide rather than directly with the enzyme $(33,34)$. Finally, a $\mathrm{Cl}^{-}$requirement was based on the inhibitory effects of $\mathrm{Cl}^{-}$-free conditions on chloramine formation. These results are not surprising since the oxidant being measured is itself a chlorinated derivative. Although neutrophils incubated in $\mathrm{Cl}^{-}$-free buffers may have altered functions, neither exogenous $\mathrm{H}_{2} \mathrm{O}_{2}$ nor myeloperoxidase stimulated chloramine generation. Thus, it appears that intact neutrophils can utilize the $\mathrm{H}_{2} \mathrm{O}_{2}$-myeloperoxidase$\mathrm{Cl}^{-}$system to generate an oxidant capable of chlorinating taurine. Based on the demonstrated ability of the myeloperoxidase system to peroxidize $\mathrm{Cl}^{-}$to $\mathrm{HOCl}$, it would seem that this is the most likely species responsible for chloramine formation. Although this conclusion is indirect, it should be reemphasized that myeloperoxidase does not directly chlorinate organic $\mathrm{Cl}^{-}$acceptors and has not been demonstrated to generate any other chloride oxidation products $(10,11)$.

$\mathrm{HOCl}$ is a powerful oxidant capable of reacting with a host of biologically important molecules (30-32). We have previously shown that a human tumor cell line is sensitive to low concentrations of $\mathrm{HOCl}(8)$ and Thomas (17) has demonstrated its strong bactericidal potential. Indeed, neutrophils are capable of incorporating chloride into insoluble fractions of phagocytosed bacteria (35). The reactivity of $\mathrm{HOCl}$ also suggests 
potential control mechanisms for limiting its production. HOCl generation by neutrophils would be dependent on the quantity of $\mathrm{H}_{2} \mathrm{O}_{2}$ produced, the rate of $\mathrm{H}_{2} \mathrm{O}_{2}$ catabolism by endogenous catalase or the glutathione redox system, the amount of myeloperoxidase released, and the availability of potential substrates for $\mathrm{HOCl}$. If sufficient myeloperoxidase is released but there are no available substrates for $\mathrm{HOCl}$, either myeloperoxidase $(6,10)$ or possibly NADPH oxidase itself (36) could be rapidly inactivated. In our system, 2 $\times 10^{6}$ zymosan-stimulated neutrophils generated $\sim 260$ $\mathrm{nmol}$ of $\mathrm{H}_{2} \mathrm{O}_{2}$ (based on values obtained for $2.5 \times 10^{5}$ cells) compared with $\sim 100 \mathrm{nmol}$ of taurine chloramine. We conclude that $\sim 40 \%$ of the detected $\mathrm{H}_{2} \mathrm{O}_{2}$ was utilized by the myeloperoxidase system to generate $\mathrm{HOCl}$. Although the utilization of $\mathrm{H}_{2} \mathrm{O}_{2}$ by myeloperoxidase may be maximized in our system via the maintenance of high concentrations of taurine, chloramines are oxidants that may be capable of inactivating myeloperoxidase (37). In the presence of an acceptor molecule that does not form an oxidant, even more effective utilization of $\mathrm{H}_{2} \mathrm{O}_{2}$ by myeloperoxidase might be attained.

In this study, taurine was used to trap and quantitate $\mathrm{HOCl}$, but these results also suggest that neutrophils may use amines present at inflammatory sites to generate stable chloramine derivatives. Chloramines can oxidize sulfhydryl containing compounds, thioethers, ${ }^{3}$ iodide, and may slowly hydrolyze to regenerate $\mathrm{HOCl}$ (38). Indeed, Thomas (38) has recently demonstrated the bactericidal potential of a variety of chloramines. Thus, neutrophils could also utilize the myeloperoxidase system to generate long-lived oxidants capable of mediating inflammatory effects long after the termination of the respiratory burst. Based on the demonstrated reactivity of $\mathrm{HOCl}$ and its chloramine derivatives, these neutrophil-derived oxidants should play an important role in host defense and the inflammatory response.

\section{ACKNOWLEDGMENT}

We would like to thank Drs. J. M. Albrich and E. L. Thomas for helpful discussions.

This work was supported by grant ROl AI-16524-02 from the National Institutes of Health.

\section{REFERENCES}

1. Klebanoff, S. J., and R. A. Clark. 1978. The Neutrophil: Function and Clinical Disorders. North Holland Publishing Company, Amsterdam.

2. Babior, B. M. 1978. Oxygen-dependent microbial killing by phagocytes. N. Engl. J. Med. 298: 659-668.

3. Badwey, J. A., and M. L. Karnovsky. 1980. Active oxygen

${ }^{3}$ S. J. Weiss. Unpublished observations. species and the functions of phagocytic leukocytes.Annu. Rev. Biochem. 49: 695-726.

4. Klebanoff, S. J. 1980. Oxygen metabolism and the toxic properties of phagocytes. Ann. Intern. Med. 93: 480489.

5. Agner, K. 1972. Biological effects of hypochlorous acid formed by "MPO"-peroxidation in the presence of chloride ions. In Structure and Function of Oxidation-Reduction Enzymes. A. Akeson and A. Ehrenberg, editors. Pergamon Press, Ltd., Oxford. 329-335.

6. Sbarra, A. J., R. J. Selvaraj, B. B. Paul, P. K. F. Poskitt, G. W. Mitchell, F. Louis, and M. A. Asbell. 1977. Granulocyte biochemistry and a hydrogen peroxide-dependent microbicidal system. In The Granulocyte: Functional and Clinical Utilization. T. Greenwalt and G. A. Jamieson, editors. Alan R. Liss, Inc., New York. 29-35.

7. Thomas, E. L. 1979. Myeloperoxidase, hydrogen peroxide, chloride antimicrobial system: nitrogen-chlorine derivatives of bacterial components in bactericidal action against Escherichia coli. Infect. Immun. 23: 522531.

8. Slivka, A., A. F. LoBuglio, and S. J. Weiss. 1980. A potential role for hypochlorous acid in granulocyte-mediated tumor cell cytotoxicity. Blood. 55: 347-350.

9. Weiss, S. J., and A. Slivka. 1982. Monocyte and granulocyte-mediated tumor cell destruction: a role for the hydrogen peroxide-myeloperoxidase-chloride system. $J$. Clin. Invest. 69: 255-262.

10. Harrison, J. E., and J. Schultz. 1976. Studies on the chlorinating activity of myeloperoxidase. J. Biol. Chem. 251: 1371-1374.

11. Morrison, M., and G. R. Schonbaum. 1976. Peroxidasecatalyzed halogenation. Annu. Rev. Biochem. 45: 861888.

12. Zgliczynski, J. M., T. Stelmaszynska, J. Domanski, and W. Ostrowski. 1971. Chloramine as intermediates of oxidation reaction of amino acids by myeloperoxidase. Biochim. Biophys. Acta. 235: 419-424.

13. Stelmaszynska, T., and J. M. Zgliczynski. 1974. Myeloperoxidase of human neutrophilic granulocytes as chlorinating enzyme. Eur. J. Biochem. 45: 305-312.

14. Stelmaszynska, T., and J. M. Zgliczynski. 1978. N-(2oxoacyl)amino acids and nitriles as final products of dipeptide chlorination mediated by the myeloperoxidase/ $\mathrm{H}_{2} \mathrm{O}_{2} / \mathrm{Cl}^{-}$system. Eur. J. Biochem. 92: 301-308.

15. Weiss, S. J., P. K. Rustagi, and A. F. LoBuglio. 1978. Human granulocyte generation of the hydroxyl radical. J. Exp. Med. 147: 316-323.

16. Clark, R. A., and S. Szot. 1981. The myeloperoxidasehydrogen peroxidase-halide system as effector of neutrophil-mediated tumor cell cytotoxicity. J. Immunol. 126: 1295-1301.

17. Homan-Muller, J. W. T., R. S. Weening, and D. Roos. 1975. Production of hydrogen peroxide by phagocytizing human granulocytes. J. Lab. Clin. Med. 85: 198207

18. Harrison, J. E., S. Pabalan, and J. Schultz. 1977. The subunit structure of crystalline canine myeloperoxidase. Biochim. Biophys. Acta. 493: 247-259.

19. Worthington Enzyme Manual. 1972. Worthington Biochemical Corp., Freehold, NJ.

20. McCord, J. M., and I. Fridovich. 1969. Superoxide dismutase. An enzymic function for erythrocuprein (hemocuprein). J. Biol. Chem. 244: 6049-6055.

21. Morris, J. S. 1966. The acid ionization constant of $\mathrm{HOCl}$ from 5 to $35^{\circ}$. J. Phys. Chem. 70: 3798-3805. 
22. Ellman, G. L. 1959. Tissue sulfhydryl groups. Arch. Biochem. Biophys. 82: 70-77.

23. Alexander, N. M. 1962. A spectrophotometric assay for iodide oxidation by thyroid peroxidase. Anal. Biochem. 4: 351-355.

24. Thurman, R. G., H. G. Ley, and R. Scholz. 1972. Hepatic microsomal ethanol oxidation. Eur. J. Biochem. 25: 420430.

25. Danehy, J. P., V. J. Elia, and C. J. Lovelle. 1971. The alkaline decomposition of organic disulfides. IV. A limitation on the use of Ellman's reagent, 2,2-dinitro-5,5'dithiodibenzoic acid. J. Org. Chem. 36: 1003-1005.

26. White, J. G., and R. E. Estensen. 1974. Selective labilization of specific granules in polymorphonuclear leukocytes by phorbol myristate acetate. Am. J. Pathol. 75: 45-54.

27. Wright, O. G., D. A. Bralove, and J. I. Gallin. 1977. The differential mobilization of human neutrophil granules. Am. J. Pathol. 87: 273-281.

28. Clark, R. A., and S. Szot. 1982. Chemotactic factor inactivation by stimulated human neutrophils mediated by myeloperoxidase-catalyzed methionine oxidation. $J$. Immunol. 128: 1507-1513.

29. Paredes, J-M., and S. J. Weiss. 1982. Human neutrophils transform prostaglandins by a myeloperoxidase-dependent mechanism. J. Biol. Chem. 257: 2738-2740.

30. Downs, A. J., and C. J. Adams. 1973. In Comprehensive Inorganic Chemistry. J. C. Bailar, H. J. Emeleus, R. Nyholm, and A. F. Trotman-Dickenson, editors. Pergamon Press, Ltd., Oxford. 1399-1412.
31. Albrich, J. M., C. A. McCarthy, and J. K. Hurst. 1981. Biological reactivity of hypochlorous acid: implications for microbicidal mechanisms of leukocyte myeloperoxidase. Proc. Natl. Acad. Sci. U.S.A. 78: 210-214.

32. Selvaraj, R. J., J. M. Zgliczynski, B. B. Paul, and A. J. Sbarra. 1980. Chlorination of reduced nicotinamide adenine dinucleotides by myeloperoxidase: a novel bactericidal mechanism. J. Reticuloendothel. Soc. 27: 3138.

33. Morris, D. R., and L. P. Hager. 1966. Mechanism of the inhibition of enzymatic halogenation by antithyroid agents. J. Biol. Chem. 241: 3582-3589.

34. Davidson, B., U. Soodak, H. V. Strout, J. T. Neary, C. Nakamura, and F. Maloof. 1979. Thiourea and cyanamide as inhibitors of thyroid peroxidase: the role of iodide. Endocrinology. 104: 919-924.

35. Zgliczynski, J. M., and T. Stelmaszynska. 1975. Chlorinating ability of human phagocytosing leukocytes. Eur. J. Biochem. 56: 157-162.

36. Jandl, R. C., J. André-Schwartz, L. Borges-Dubois, R. S. Kipnes, B. J. McMurrich, and B. M. Babior. 1978. Termination of the respiratory burst in human neutrophils. J. Clin. Invest. 61: 1176-1185.

37. Naskalski, J. W. 1977. Myeloperoxidase inactivation in the course of catalysis of chlorination of taurine. Biochim. Biophys. Acta. 485: 291-300.

38. Thomas, E. L. 1979. Myeloperoxidase-hydrogen peroxide-chloride antimicrobial system: effect of exogenous amines on antibacterial action against Escherichia coli. Infect. Immun. 25: 110-116. 